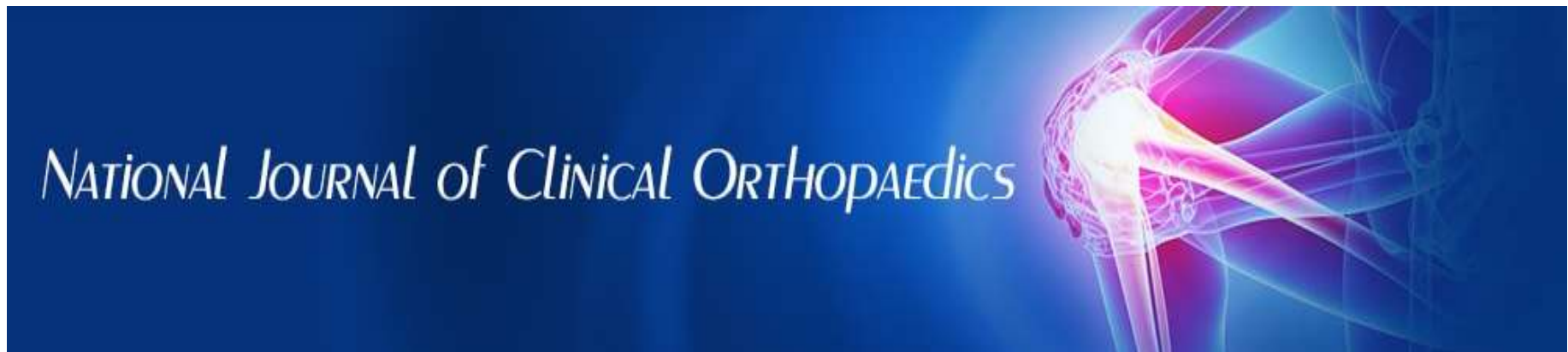

ISSN (P): 2521-3466 ISSN (E): 2521-3474 (C) Clinical Orthopaedics www.orthoresearchjournal.com 2021; 5(1): 109-113

Received: 12-11-2020

Accepted: 15-12-2020

Manjunath S Japatti Department of orthopaedic, Lalith orthopaedic hospital Sulepeth. Chincholi, Kalburgi,

Karnataka, India

Pavith T Janardhan

Senior Resident, Kodagu institute of medical sciences, Madikeri, Karnataka, India
Corresponding Author: Manjunath S Japatti Department of orthopaedic, Lalith orthopaedic hospital Sulepeth. Chincholi, Kalburgi,

Karnataka, India

\section{A prospective interventional study of external fixator and delta frame as primary and definitive mode of treatment for open tibial fractures}

\author{
Manjunath S Japatti and Pavith T Janardhan
}

DOI: https://doi.org/10.33545/orthor.2021.v5.i1b.294

\section{Abstract}

Background: Open tibial fractures are most common injuries involving the lower limb. Most of the injuries are due to high energy impact occurring during RTA. Fractures are associated with multiple soft tissue injuries and skin loss leading to high chance of infection and non-union, need for multiple procedures. Managing these fractures with external fixators including delta frame along with debridement were the standard procedure. This study aims at analysing the use of external fixators as definitive mode of treatment and occurrence of complications.

Methods: This is a prospective interventional study of 30 cases of open tibial diaphyseal fracture treated surgically with ex fix and assessed for functional outcome and complications. Which were admitted to Lalith orthopaedic hospital Chincholi between 2015 to 2017. External fixator and delta frames were used for fracture fixation with debridement. Outcome analysed at the end taking into consideration of time to union, complications and need for reoperation.

Results: All 30 patients were achieved union with external fixation and delta frame alone. Overall mean union time was 24 weeks. Time to union along with complications were more for type III B fractures. $33 \%$ ( 1 case out of 3 ) proximal fracture showed varus malunion.34\% ( 2 cases out of 7$)$ of distal third fracture showed valgus malunion. 12 cases (40\%) developed superficial pin tract infection irrespective of Gustilo Anderson classification. Ankle stiffness noted in distal third shaft fracture managed with delta frame.

Conclusions: Debridement and external fixation for diaphyseal fracture tibia and delta frame for distal third extra articular tibia fracture can serve as definitive treatment modality provided anatomical reduction achieved with no bone loss. Ankle stiffness was reported in all post delta frame ankle immobilization raising need for physiotherapy immediately after frame removal. Ex fix as a definitive fixation reduces the risk of multiple staged operative procedures which are usually conducted after settling of soft tissue injuries.

Keywords: Open fracture, external fixator, delta frame, pin tract infection

\section{Introduction}

Tibia is the most common bone to get injured in lower limb trauma. Due to its subcutaneous nature most of the tibial fractures results in exposing the underlying bone. Open fractures of tibia are mostly due to RTA specially two-wheeler accidents and pedestrian accidents. Most of the tibia open fractures are associated with soft tissue injuries, swelling or bad skin conditions. This precludes internal fixation with nailing and plating. Stabilisation of fracture by this method avoids extensive soft tissue injury which usually occurs with internal fixation. This is less invasive compared open reduction and plating ${ }^{[1]}$.

Initially thorough debridement and external fixator or delta frame fixator is a standard practice of care for these fractures. In later stages some cases may require soft tissue coverage and other additional fixation methods like intramedullary nailing or plating. External fixator may be later converted to internal fixation with reamed or unreamed intramedullary nail or continued as definitive treatment ${ }^{[2]}$. Present study focuses on using external fixators as definitive management for open tibial fractures. 


\section{Methods}

This is a prospective study of 30 cases of open tibial fracturs classified according to Gustilo Anderson classification. All cases treated surgically with thorough debridement and external fixation or delta frame fixation. Adult Patients with isolated open tibial fracture due to RTA attending to causality and outpatient department were primarily evaluated to exclude neurovascular injury and head and abdomen injury. Finally, patient was evaluated with radiography and arterial doppler. Patients are selected for the study depending on the inclusion and exclusion criteria. AO external fixator or delta frame was used as External fixation of all cases. Post-operative Evaluation of the patient's clinical and functional outcome regarding union rate, time taken to unite, knee and ankle movements and complications like pin tract infection were analysed with respect to its type as per Gustilo Anderson classification. Follow up carried at regular intervals of 6 weeks, 3months, 6months, 12 months, 18 months and 24 months intervals and same will be recorded in a specialised case form.

\section{Results}

The present study involves 33 cases of open tibial fracture with variable soft tissue injuries. However, 30 cases were available for final follow-up. We lost 3 cases due to unknown reasons. All patients were treated by thorough debridement and external fixation with AO External fixators. In our study the age distribution ranges from 20 to 60 years ,8 (26\%) patients were between 21-30 years, $10(33 \%)$ were between $31-40$ years and $7(23 \%)$ were between $41-50$ years. $5(23 \%)$ cases were between 51-60 years. The mean age was 33.6 years. Maximum incidence of injury occurred between $31-40$ years i.e., 10 cases $(33 \%)$. Sex wise 23(75\%) male and $7(23 \%)$ female patients were seen with male to female ratio 3:1. Laterality wise left tibia involved in $17(60 \%)$ cases compared to right $13(40 \%)$. Mode of injury was RTA and fall from height in equal number of populations i.e. 15 case each (50\% each). According to Gustilo Anderson classification in our study we didn't had type 1 fracture. There were $17(56 \%)$ cases of type II fracture, 10(33\%) was type III A fracture, $3(9 \%)$ were type III B fracture. Upper third tibia was involved in $3(10 \%)$ cases, middle third involved in $18(60 \%)$ cases. Lower third extra articular involved in 7 (23\%) cases. Associated fractures were seen as follows. Both bone forearm fracture in one patient, distal radius in another patient, clavicle in another 2 patients. All cases were operated on emergency basis within 6 hours. Early mobilization started for all cases from $3^{\text {rd }}$ post-operative day. No significant post op complications encountered. Mean time noted to fracture union for type II Fractures were 18 weeks, for type III A 24week and for type III B it was 30 weeks. Varus malalignment is seen in 1 case $(3 \%)$ of proximal third tibia fracture. valgus malalignment was seen in 2 $(6 \%)$ distal third tibia fracture. 12 cases $(39 \%)$ of superficial pin tract infection were noticed and managed with antibiotics. All infections were effectively resolved. No case developed osteomyelitis during the period of follow-up. Knee range of movements unaffected in all cases including proximal third fracture. However distal third tibia fracture treated delta frame developed significant ankle stiffness requiring physiotherapy for more than 3 weeks.

\section{Discussion}

Open tibia fractures are one of the most difficult fractures to treat. The soft tissue status, the degree of comminution and bone loss, vascular injury, level of the fracture sustained determines the final results ${ }^{[3]}$. The aim of surgery is to obtain anatomic reduction of the fracture with soft tissue preservation and thorough debridement and providing stability ${ }^{[4,5]}$. This should be achieved using procedures that decrease bony and soft tissue de vascularization. Failure to recognize this often results in repeated surgery and even amputation ${ }^{[6]}$. AO external fixator and delta frame is one such modality ${ }^{[7]}$. However external fixation do has certain inbound complications like risk of pin tract infection and loss of reduction in external fixation. These serious complications can be tackled by appropriate measures ${ }^{[8}$, 9]. Though there is risk of delayed union and non-union, it may be because of injury itself to the bone and soft tissue, loss of blood supply at fracture site, anatomical location and external fixator alone cannot be attributed to the cause of delayed and non-union ${ }^{[10]}$.

The present study was under taken to emphasise the efficacy of the external Fixator in treatment of the open fractures of the tibia. We evaluated our results and various factors are discussed. Our studies shown the average age of patients with above injuries to be 33.6 years (Range 21 to 60 years) which is comparable to that of other studies. In our study, the male preponderance was high $69 \%$ (23 cases) compared to the female $25 \%$ (7cases) similar to study by done by Barbieri et al. which was $59 \%{ }^{[11]}$. In our study all cases were due to high energy trauma accounting to $100 \%$ cause. Gaudinez et al. observed $93 \%$ high energy fractures in his study ${ }^{[12]}$. Another study conducted by Agarwal et.al who noticed $87 \%$ patients with high energy injuries ${ }^{[13]}$. In our study road traffic accident (80\%) was the predominant mode of violence apart fall from height.

The results of external fixation were reported to be good by Barbieri 90\%, Marsh 69\%, Bone 95\% and Tornetta ${ }^{[13,14,15]}$. A meta-analysis of randomized prospective study comparing external fixator with unreamed nailing showed no statistically significant difference between the two methods ${ }^{[16]}$. However many other studies report superiorities of external fixator as initial mode of treatment in open fractures. In our studies we found $56 \%$ (17 cases) of type II injuries, 33\% (10 cases) type III $\mathrm{A}$ and $9 \%$ (3 cases) type III B Fractures. Normal union is defined as union occurring within 6 months. Union is said to be delayed union if union occurs over period of $6-8$ months. Fractures fail to show any union beyond 8 months are said to be having non-union and warrants further investigation and different mode of treatments. In this study average time taken by type II fracture to show union is 18 weeks, type III A fracture took 24 weeks and type III took 30 weeks. Which is in par with following studies. Giannoudis et al. in 536 open fractures treated by external fixator of which $82 \%$ were Grade III open injuries, the incidence of delayed union was $24 \%{ }^{[17]}$. We noticed $40 \%$ (12 cases) of pin tract infection randomly distributed among all types irrespective of severity of injury.

All are managed conservatively with antibiotics.no case required pin exchange .no case was in need of implant replacement. Following study also reports occurrence of complications but with different frequency. Michail Beltrios et al. reported $87.27 \%$ union, 18 non-union, 21 delayed union and 4 mal-unions, pintract infection $26.36 \%$ and osteomyelitis in 3 cases [1.36\%] in their study of 212 patients treated with external fixator as a definitive treatment ${ }^{[18]}$. 


\section{Case 1}

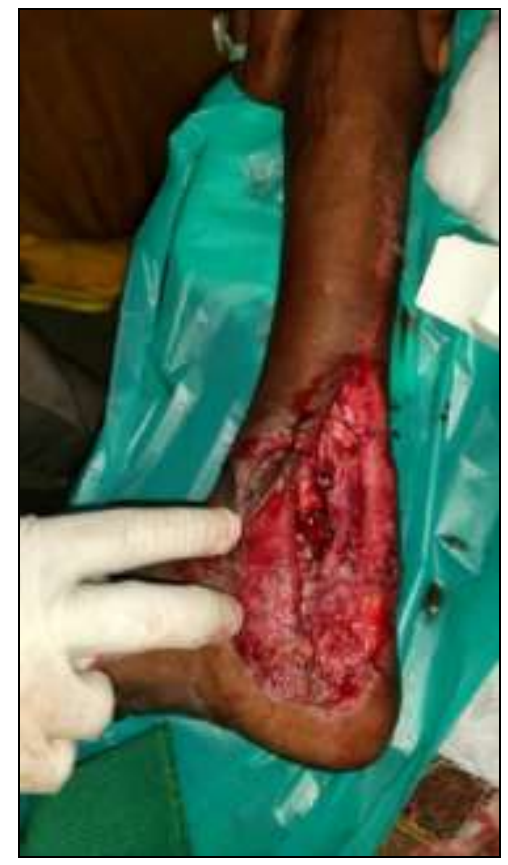

Fig 1: Pre op

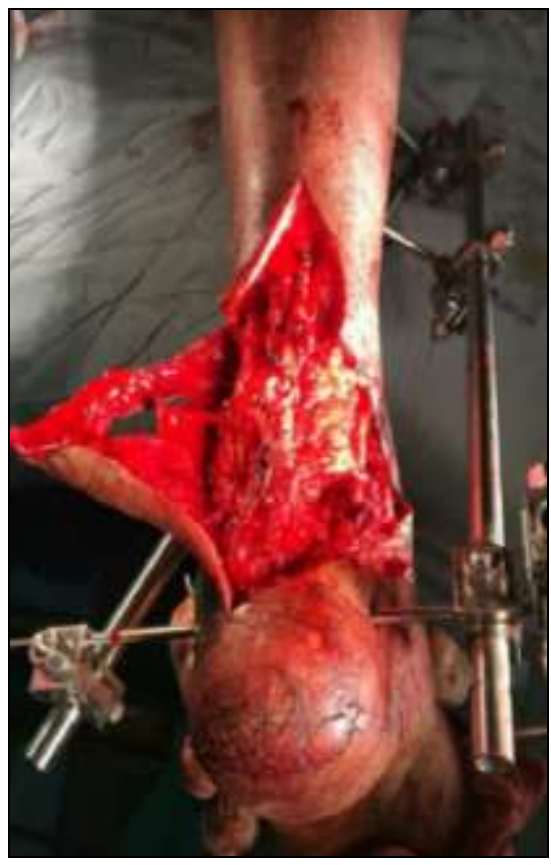

Fig 2: Intra op -torn TA tendon

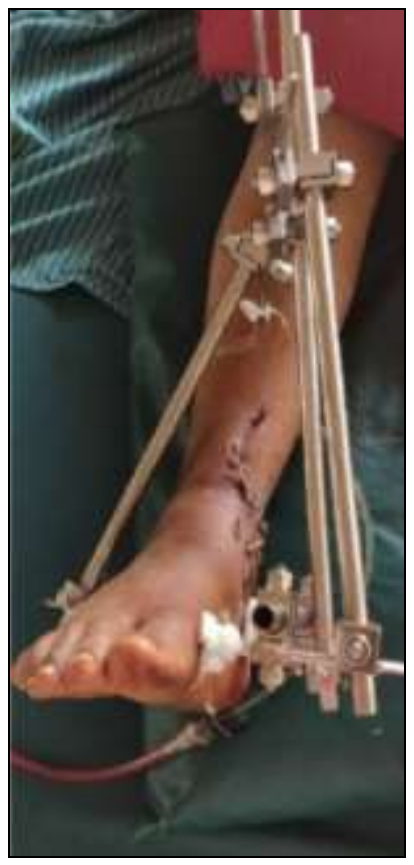

Fig 3: Post op

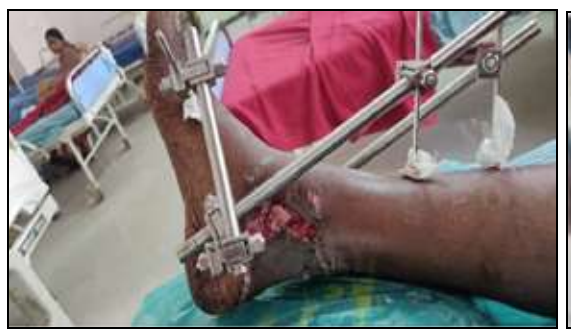

Fig 4: Early post op

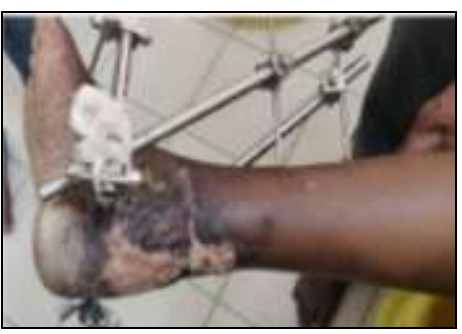

Fig 5: 2 months later

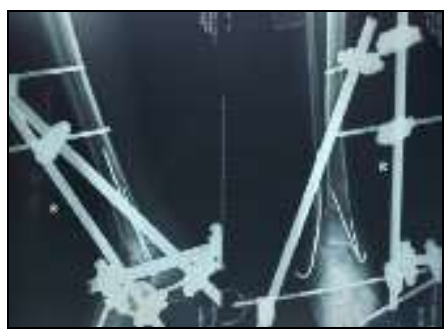

Fig 6: Post op

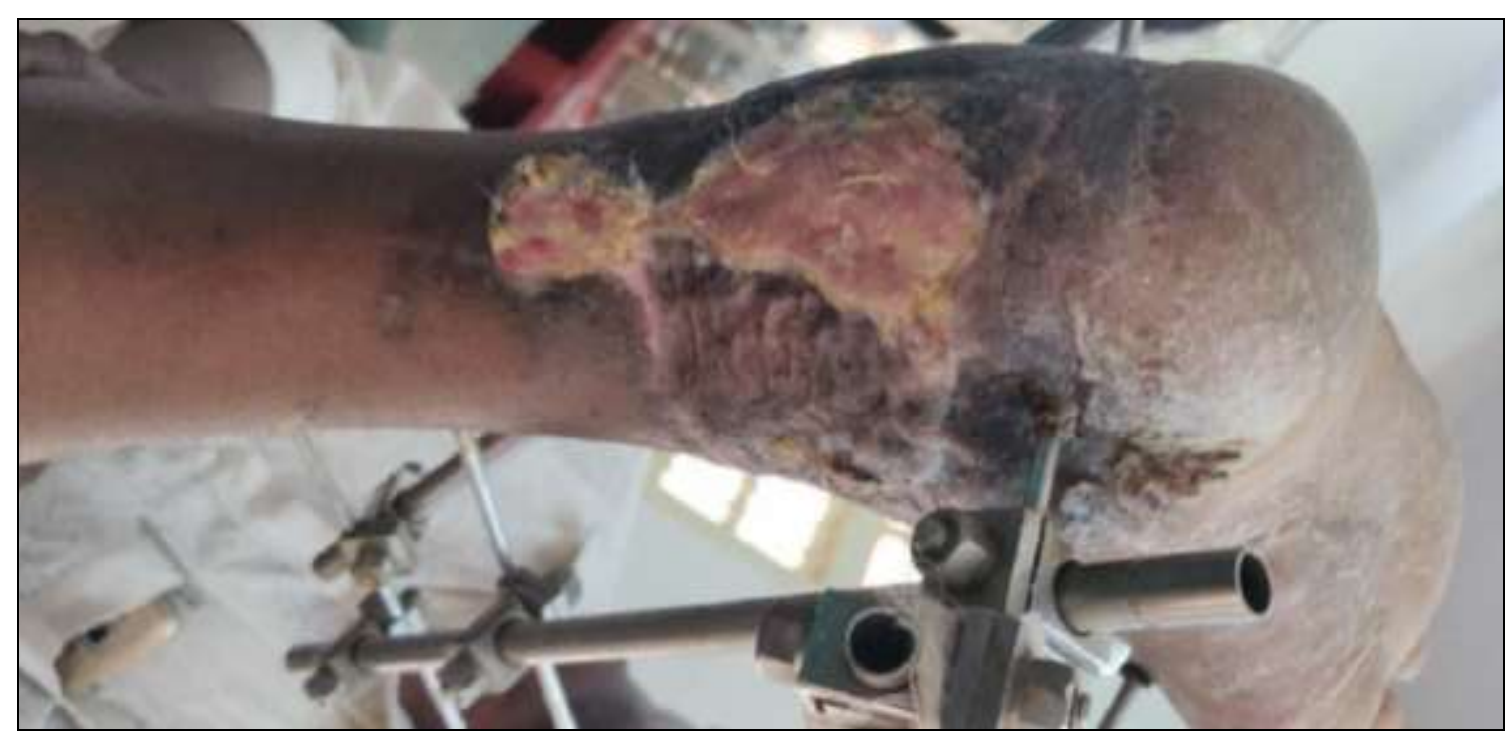

Fig 7: Healing soft tissue - TA Tendon and skin 3 months post op 


\section{Case 2}
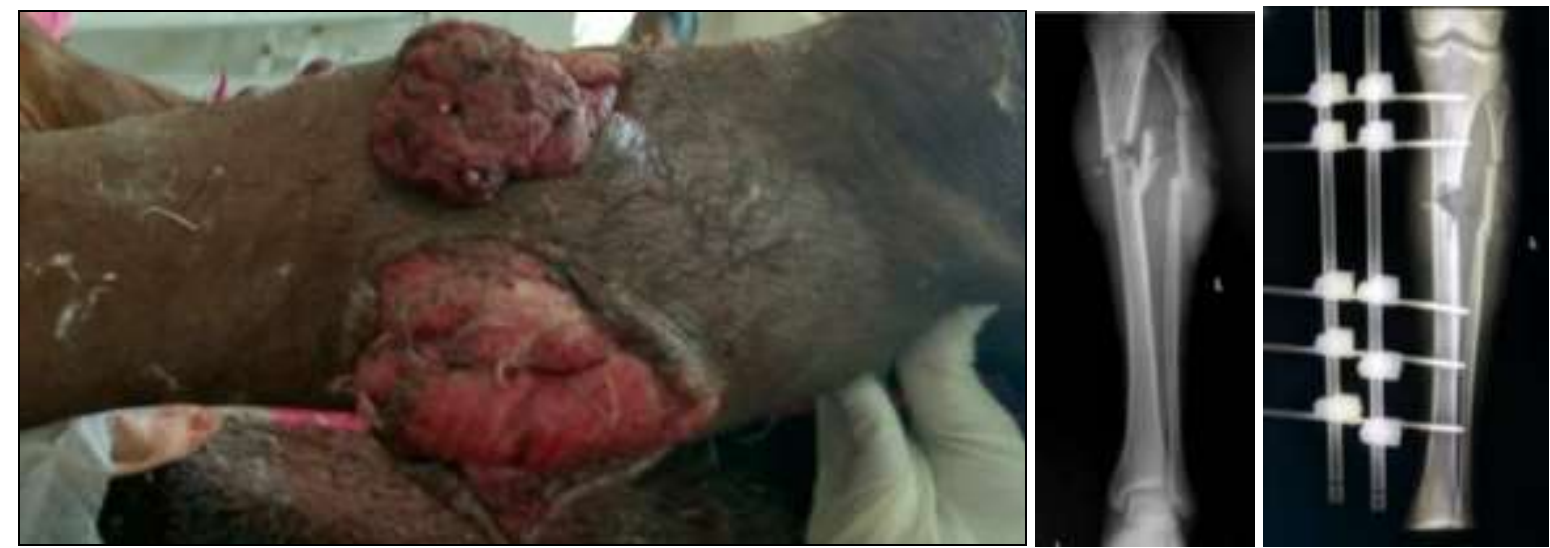

Fig 8: Type III B Open fracture tibia fibula Fig:9 pre op Fig; 10 postop

\section{Case 3}

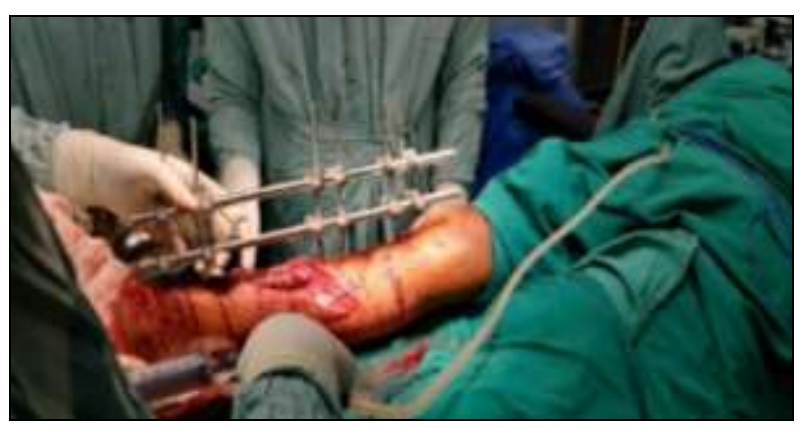

Fig 11: Intra op segmental fracture

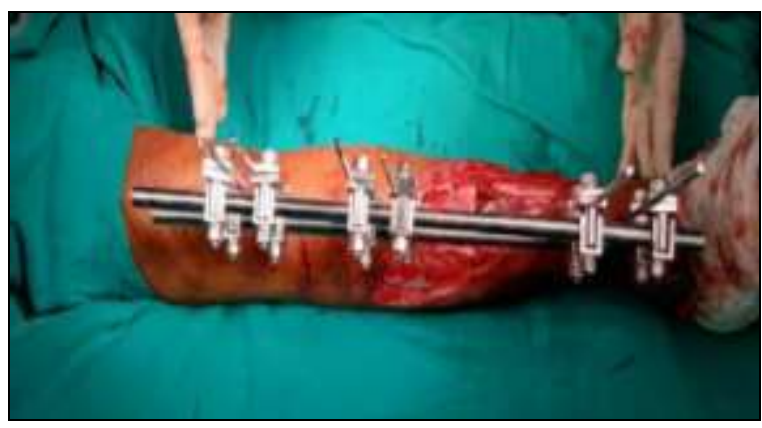

Fig 12: Intra op

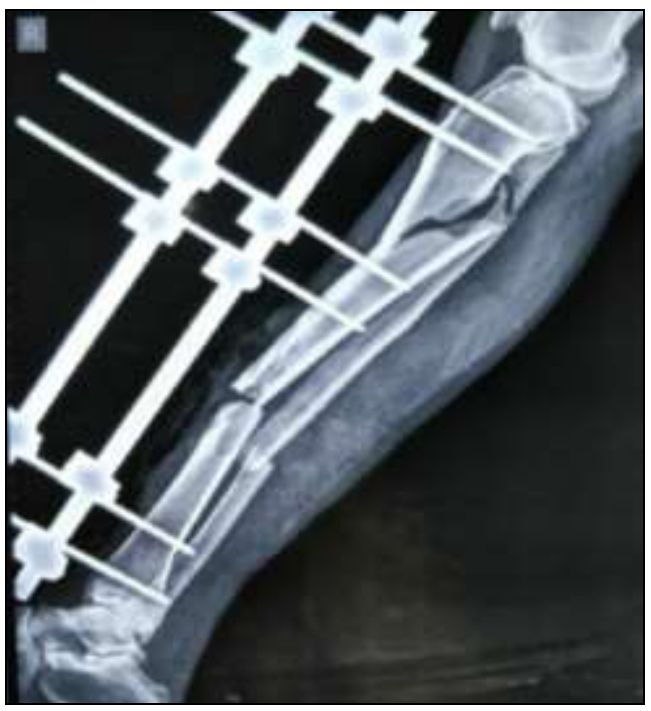

Fig 13: Post op lateral

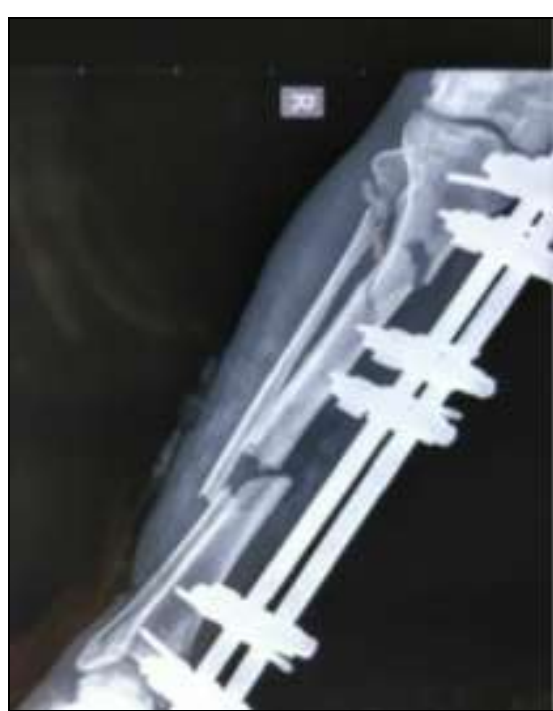

Fig 14: Post Op Ap

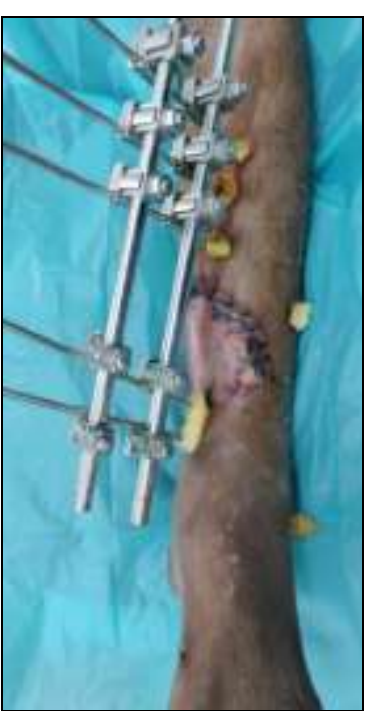

Fig 15: Post op 


\section{Case 4}

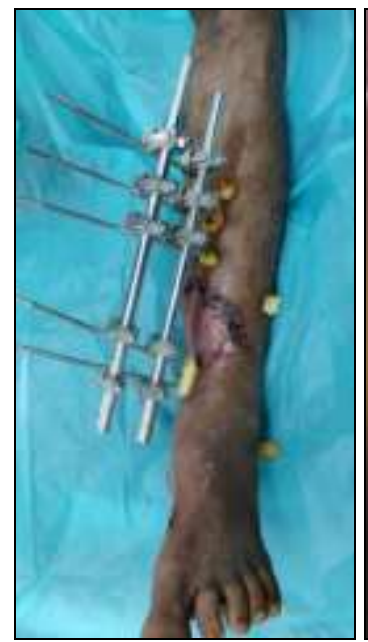

Fig 16: Post op
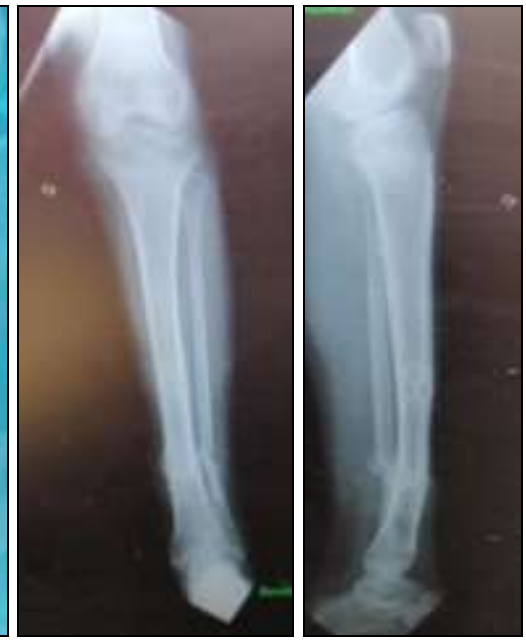

Fig 17: Valgus Malunion

\section{Conclusion}

External fixators and delta frame applications for open tibial fractures with significant soft tissue compromise proves an effective modality of treatment which not only serves as a definitive fixation but also minimises soft tissue insult. It preserves the biology of fracture providing simultaneous stable fixation.

\section{Declarations}

Funding: none

\section{Conflict of interest: none}

Ethical approval: taken

\section{References}

1. Saleh M, Shanahan, Fern ED. Intraarticular fractures of the distal tibia. Surgical management by limited internal fixation and articulated distraction. Injury 1993;24(1):3740.

2. Ruedi TP, Allgower M. The operative treatment of intra articular fractures of the lower end of tibia. Clin Orthop 1979;138:105-110.

3. Thomas P Raedei, William M Maphy. AO principles of fracture management. 617-637.

4. Giannoudis PV, Papakostidis C, Roberts C. A review of management of open fracture of tibia and femur. JBJS 2006;3(88B):281-289.

5. Robert W Bucholz, James D Heckman, Charles M, Court Brown. Rock wood and Green fracture in adults, 6th Edition, 20792014.

6. Wyrsch B, McFerran M, McAndrew M. Operative treatment of fractures of the tibial plafond. A randomized prospective study. J Bone Joint Surg 1996;78-A:1646-57.

7. Gustilo RB, Merkow RL, Templeman D. The management of open fractures. J Bone Joint Surg Am 1990;72:299-304.

8. Clifford RP, Lyone TJ, Webb JK. Complication of external fixator in open fractures of Tibia. Injury 1987;18(3):174176.

9. Gustilo RB, Anderson JT. Prevention of infection in the treatment of one thousand and twenty-five open fractures of long bones: Retrospective and prospective analyses. J Bone Joint Surg Am. 1976;58:453-8.

10. Caudle RJ, Stemp J. severe open fracture of tibia, JBJS
[Am] 1987;69-A:801-807.

11. Barbieri R, Schenk R, Koval K. Hybrid external fixation in the treatment of tibial plafond fractures. Clin Orthop 1996;332:16-22.

12. Gaudinez, et al. observed $93 \%$ high energy fractures in his study. Another study conducted by.

13. Agarwal, et al. v40 who noticed $87 \%$ patients with high energy injuries. In our study road traffic accident (80\%) was the predominant mode of violence apart fall from height.

14. Marsh JL, Bonar S, Nepola JV. Use of an articulated external fixator for fractures of the tibial plafond. $J$ Bone Joint Surg 1995;77-A:1498-509.

15. Tornetta P, Weiner L, Bergman M. Pilon fractures: treatment with combined internal and external fixation. J Orthop Trauma 1993;7:489-96.

16. Bhandari M, Guyatt GH, Swiontkowski MF, Schemitsch $\mathrm{EH}$. Treatment of open fractures of the shaft of the tibia: a systematic overview and meta-analysis. J Bone Joint Surg [Br] 2001;83-B:62-8.

17. Giannoudis PV. Surgical priorities in damage control orthopaedics. J Bone Joint Surg. [Br] 2003;85-B:478-83.

18. Michail Beltrias, Olga Sarridou, John Kovam's, et al. external fixation on a primary and treatment for tibial diaphyseal fracture strategies trauma limb reconstruction 2009;4(2):81-87. 